\title{
Compact and user-friendly ultrasound acquisition systems optimized for field recording
}

\author{
RAIMUND SPECHT \\ Avisoft Bioacoustics, Hauptstr. 52, 13158 Berlin, Germany \\ Manuscript received on January 15, 2004; accepted for publication on February 5, 2004.
}

\begin{abstract}
A compact and rugged hardware interface for laptop-based ultrasound recording in the field has been developed. The versatile devices overcome the limitations and drawbacks of previously available solutions. The accompanying recording software enables flexible hard disk recording for both manual and automated operation.
\end{abstract}

Key words: ultrasound recording, laptop-based sound recording, long-term acoustic monitoring, sound analysis.

\section{INTRODUCTION}

Until recently, the opportunities for recording ultrasonic animal vocalizations in the field were limited (see Pye 1992). The commonly used timeexpansion bat detectors have a low dynamic range (8 bits only) and do not support continuous recording over longer periods of time (Jones et al. 2000). On the other hand, high-speed tape recorders are bulky and very expensive, while high-speed PCMCIA data acquisition cards installed in laptop computers suffer from fragile connectors and the lack of anti-aliasing filters. For these reasons, Avisoft Bioacoustics designed specialized hardware as a solution for mobile ultrasound recording.

\section{HARDWARE}

The new compact devices $(56 \times 35 \times 140 \mathrm{~mm}$, Fig. 1) integrate an adjustable pre-amplifier, a highspeed 16-bit A/D converter with anti-aliasing filter (sigma-delta type), a peak-level meter to prevent over-modulation, an acoustic monitor for making

E-mail: raimund.specht@ avisoft.de, www.avisoft.info the ultrasound audible to the human ear, a trigger button, a TTL-compatible digital input and a buspowered USB interface for reliable operation from a laptop computer (Fig. 2). The rugged XLR input socket allows the connection of a microphone either directly or using an intermediate extension cable of up to $20 \mathrm{~m}$ length. A 4-channel version (USG 416) supports simultaneous sampling at a sampling rate of $500 \mathrm{kHz}$ at 16 bit or $750 \mathrm{kHz}$ at 8 bit.

The model USG 124 supports $24 \mathrm{bit} / 192 \mathrm{kHz}$ sampling and does not feature the ultrasound monitor. Instead, it provides a switchable $48 \mathrm{~V}$ phantom power supply for feeding high-quality condenser microphones. This model is targeted at both audiorange and ultrasound recording applications (e.g. for bird or grasshopper songs).

\section{SOFTWARE}

The accompanying recording software (Russ 2003) provides a real-time spectrographic display and versatile triggering options, which also include a pretrigger recording mode and a virtual heterodyne 


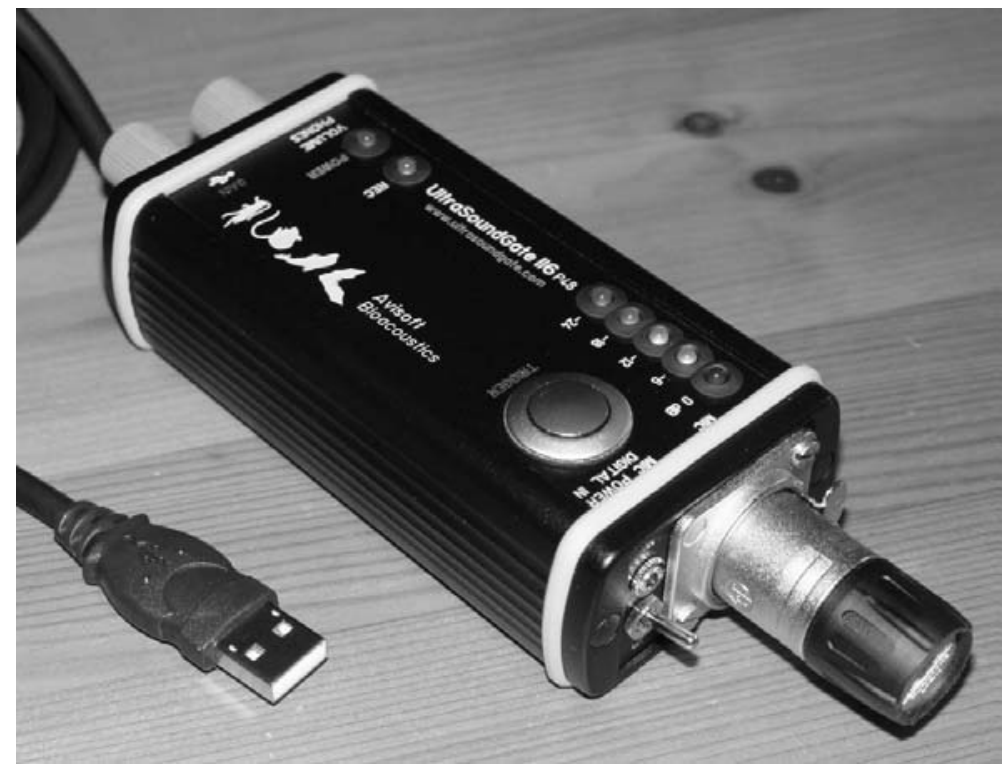

Fig. 1 - UltraSoundGate 116.

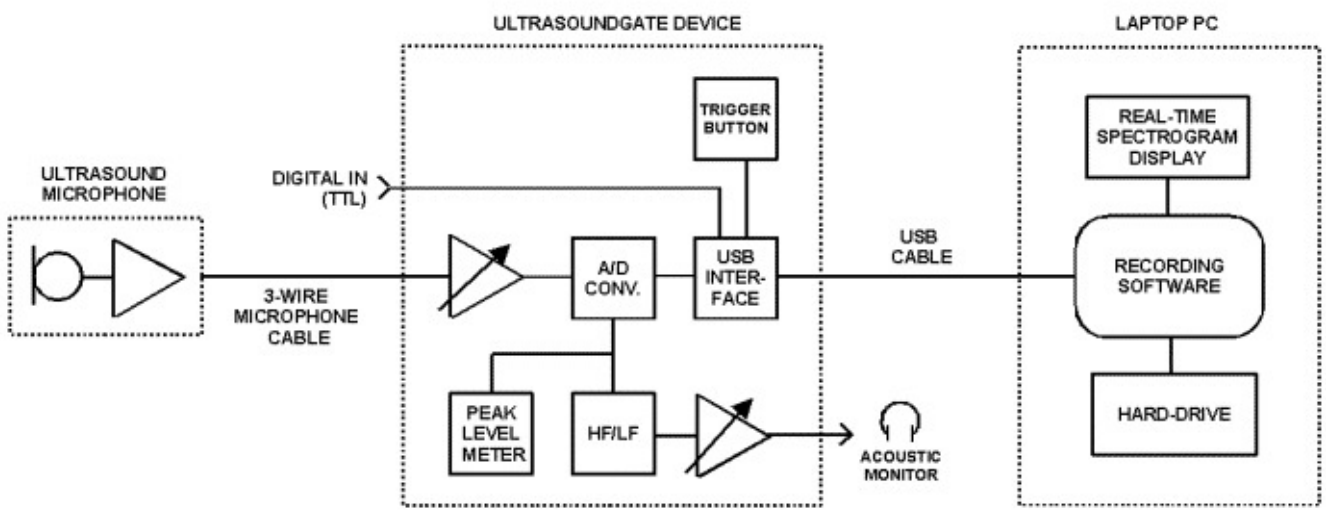

Fig. 2 - Principle of the UltraSoundGate system.

monitoring feature. The acquired sounds are stored directly into common .wav files, enabling hasslefree analysis for different sound analysis packages (McGregor 1995). The hardware interface is represented in the operating system as a standard audio recording device and the trigger button appears to the PC software as a standard joystick button. This allows the use of any other sound recording software, including custom-written programs for special-purpose applications.
There is no need to install any device-specific drivers, because the devices use the native drivers already implemented in the operating system. There is therefore no risk of obsolescence with future operating systems, which might be the case had devicespecific drivers been used.

For convenience, the RECORDER software can also be configured for an automated start after booting the computer. 


\section{APPLICATIONS}

The compact size and the ease of use make the UltraSoundGate device well suited for mobile hard disk recording in the field. The peak-level meter, the acoustic monitor and especially the trigger button, that can remotely control the hard-disk recording process (while the laptop is stored in a backpack), are unique features for this application. Additionally, the real-time spectrographic display on the accompanying recording software can be used for immediate evaluation of the incoming sounds.

Alternatively, the ultrasound recording interface and the laptop could be deployed at a fixed place in the field. For that specific application, the laptop could also be replaced by a cheaper low-power single-board PC powered from a large lead-acid battery. In such a set-up, the overall power consumption of the recording system can be reduced down to about 3 watts. A common 12V/36Ah lead-acid car battery would provide a continuous operating time of about 6 days. For that application, the recording software can be configured to capture sounds in a sound-activated mode. The same mode of operation can also be used for conducting behavioral experiments in the laboratory.

The standard XLR-input socket allows interfacing with various microphones: either costeffective electret-type models or condenser microphones with flatter frequency responses. With appropriate high-impedance pre-amplifiers, hydrophones could also be attached.

\section{RESUMO}

Foi desenvolvida uma interface compacta e robusta para gravação num "lap-top" de ultrasons na natureza. Esses equipamentos versáteis superam as limitações e os inconvenientes das soluções anteriormente disponíveis. O programa de computador instalado para gravação permite registro conveniente no disco rígido por operação manual ou automática.

Palavras-chave: gravação de ultrasons, gravação de sons em "lap-top", monitoramento acústico de longo prazo, análise sonora.

\section{REFERENCES}

Jones G, Vaughan N and Parsons S. 2000. Acoustic identification of bats from directly sampled and time expanded recordings of vocalizations. Acta Chiropterologica 2: 155-170.

McGregor PK. 1995. Equipment review: AvisoftSonograph Pro: a PC program for sonographic analysis. Anim Behav 50: 1137-1138.

PyE JD. 1992. Equipment and techniques for the study of ultrasound in air. Bioacoustics 4: 77-88.

Russ J. 2003. Equipment Review: Avisoft Recorder (version 2.7). Bioacoustics 13: 323-330. 